\title{
University Students' Subjective Knowledge of Green Computing and Pro-Environmental Behavior
}

\author{
Tunku Badariah Tunku Ahmad ${ }^{1} \&$ Mohamad Sahari Nordin ${ }^{1}$ \\ ${ }^{1}$ Institute of Education, International Islamic University Malaysia, Kuala Lumpur, Malaysia \\ Correspondence: Tunku Badariah Tunku Ahmad, Institute of Education, International Islamic University \\ Malaysia, Jalan Gombak 53100, Kuala Lumpur, Malaysia. Tel: 603-6196-5380. E-mail: tbadariah@iium.edu.my; \\ tunku26@hotmail.com
}

Received: November 18, $2013 \quad$ Accepted: December 24, $2013 \quad$ Online Published: January 21, 2014
$\begin{aligned} & \text { doi:10.5539/ies.v7n2p64 } \\ & \text { URL: http://dx.doi.org/10.5539/ies.v7n2p64 }\end{aligned}$

\begin{abstract}
This cross-sectional survey examined the structure of university students' subjective knowledge of green computing-hypothesized to be a multidimensional construct with three important dimensions-and its association with pro-environmental behavior (PEB). Using a previously validated green computing questionnaire, data were collected from 842 undergraduate students attending ten different public universities in Malaysia. The sample was split into two random halves $\left(n_{1}=400\right.$ and $\left.n_{2}=442\right)$ to allow for Factor Analysis procedures and Structural Equation Modeling (SEM) to be conducted. Principal Component Analysis extracted a three-factor structure of subjective knowledge consisting of knowledge about green computing (GC) vocabulary, computer nature or characteristics, and e-waste, while Confirmatory Factor Analysis procedures confirmed the structure's measurement validity. SEM fit statistics indicated a strong influence of subjective GC knowledge on PEB with its three extracted dimensions cumulatively explaining $37 \%$ of students' reported PEB. The results confirmed the study's hypotheses regarding the multidimensionality of subjective knowledge, the adequacy of the measurement model of subjective knowledge, and its strong positive role in influencing PEB. The article concludes with guidelines for future research in areas involving green computing, subjective knowledge and PEB with an emphasis on the conceptualization and measurement of each construct.
\end{abstract}

Keywords: green computing, subjective knowledge, pro-environmental behavior, multidimensionality of knowledge, structural equation modeling, principal component analysis, confirmatory factor analysis

\section{Introduction}

\subsection{Green Computing and Its Importance}

Green computing (GC) refers to energy-efficient computing practices and environmentally responsible use of the computer and its associated subsystems. It is both a field of study and a set of eco-friendly computing practices. Murugesan (2008) suggests that the concept is multifaceted and multidimensional, covering a broad scope of energy-efficient and hazard-free computing activities involving myriad systems, devices, hardware and software. The GC concept advanced by Murugesan also includes the dimensions of e-waste disposal and management, as well as design and manufacturing of computing systems and resources. Recent statistics reveal that a lack of green computing knowledge and education is affecting the world in negative ways. Financially according to experts, about USD \$ 212.5 billion a year is wasted on powering idle computers (Aggarwal, Garg, \& Kumar, 2012). Wasteful computer use releases unnecessary carbon emissions into the air, thereby increasing global warming. These carbon emissions, also called carbon footprint, combine with other greenhouse gases to cause increased global temperatures, smog, acid rain, droughts in some countries and floods in others. Jenkin, Webster, and McShane (2011) attributed half of the world's energy wastage to end users' wasteful habits resulting from their lack of knowledge about sustainable computing. Environmentally, improper disposal and management of e-waste affects the quality of life and health of people in some poor countries. Reportedly, the dumping of e-waste in landfills in China and Ghana is slowly poisoning the children in these countries (Claiborne, 2009; Vervynckt, 2013; The China Daily, 2011).

Across the globe, there is an increasing interest in and demand for the teaching of green computing knowledge following assertions that it is fundamental to sustaining a healthy, green environment (McDougall, 1993). Many university campuses in developed nations have long started their green education efforts. This is an important 
first step towards the adoption of green computing practices among university populations in accordance with the proposition that knowledge is the first step in the adoption process (Rogers, 2003). Ideally and logically, an individual cannot begin to adopt an idea, system or device if he or she knows little or nothing about it. According to Laroche, Tomiuk, Bergeron, and Barbaro-Forleo (2002), knowledge is key to the formation of environmentally proactive attitudes, while to Thapa, Graefe, and Meyer (2005, p. 54), "environmental knowledge is a major factor in predicting pro-environmental behaviors". Bamberg and Moser (2006) found that knowledge indirectly determines an individual's intention to act pro-environmentally through perceived behavioral control. The works of these authors underscore the role of knowledge in influencing decision-making that results in pro-environmental behavior (PEB), which in this case means "behavior that consciously seeks to minimize the negative impact of one's actions on the natural and built world (e.g. minimize resource and energy consumption, use of non-toxic substances, reduce waste production)" (Kollmuss \& Agyeman, 2002, p. 240). An individual who practices green computing by buying ENERGY STAR and EPEAT-certified hardware, donating old hardware to schools and organizations, turning off the PC when not in use, and recycling used hardware can be said to display PEB.

Recent research has identified users' lack of knowledge as the biggest barrier to the adoption of green computing behavior, practices and solutions in the IT industry. Courtney (2008) wrote that a lack of knowledge in green IT is preventing IT managers from going green. A 2011 readers' poll in Australia revealed an apparent lack of knowledge in green IT among organizations, with $25 \%$ admitting having no knowledge of what it means and $22 \%$ claiming that their organization did not know enough about green technologies to adopt green computing (Government News, 2011). Existing evidence also shows that although end-users feel it is desirable to go green, many do not know much about what it really is and what is going on, nor do they understand why there is a need to go green. Consequently, we now see innumerable efforts in the forms of pro-environmental regulations, programs, and campaigns being rigorously carried out in many parts of the world to improve users' knowledge of energy-efficient computing practices; as well as experimentations and innovations within the ICT industry to enhance the energy efficiency of computers and reduce their toxicity. These are done with the aims of reducing the hazardous impact of computers on the environment and increasing users' green computing knowledge, hence the likelihood of their engaging in green compliant behaviors.

\subsection{Pro-Environmental Behavior and the Role of Subjective Knowledge}

Knowledge refers to the amount of information held in an individual's memory system that influences the way he or she assesses, interprets and reacts to environmental stimuli (Blackwell, Miniard, \& Engel, 2001). It may be classified into subjective and objective types (Brucks, 1985). While objective knowledge consists of specific and accurate facts about a given phenomenon, subjective knowledge is self-reported and reflects an individual's assessment of what and how much he or she knows about the phenomenon. Both are partially the result of experience, but they are distinct constructs and have different effects on behavior (Flynn \& Goldsmith, 1999; Xiao et al., 2010). Although subjective knowledge is often an overestimate of what individuals actually do know about a given issue (Alba \& Hutchinson, 2000; Maleki \& Karimzadeh, 2011), it may be used as a proxy for objective or actual knowledge given the statistically reliable association consistently found between them across studies (Brucks, 1985; Carlson, Vincent, Hardesty, \& Bearden, 2009; Tunku-Ahmad, Nordin, \& Bello, 2013a).

In several studies, subjective knowledge was discovered to be a stronger driver of behavior and decision-making than objective knowledge (Feick et al., 1992; Gámbaro, Ellis, \& Prieto, 2013; House et al., 2004; Pieniak et al., 2006; Radecki \& Jaccard, 1995; Sirieix et al., 2011; Xiao et al., 2010). Ellen (1994) and Aertsens et al. (2011) found subjective knowledge to be positively associated with more PEB variables than objective knowledge. In Pieniak, Aertsens, and Verbeke (2010), subjective knowledge was significantly, strongly and directly related to PEB in contrast to objective knowledge which only showed an indirect impact. All these observations make a lot of sense if we look at subjective and objective knowledge in terms of direct and indirect experience. For example, physically being in Guiyu, China (said to be the world's e-waste capital) would teach students more valuable lessons about hardware recycling and environmental pollution (direct experience/subjective knowledge) than listening to lectures about the dangers of toxic e-waste (indirect experience/objective knowledge). According to Kollmuss and Agyeman (2002), direct experiences have a stronger influence on behavior than indirect experiences. Thus, it makes sense to suggest that greater subjective knowledge as a product of direct experience would more likely persuade individuals to adopt a new idea or product, and increase the likelihood of engaging in PEB.

As asserted by Boccaletti and Moro (2000), a proper understanding of subjective knowledge is important as it provides a measure to estimate an individual's acceptance of a new idea, such as green computing behavior. Moon and Balasubramanian (2001) made the same observation after discovering a positive correlation between 
subjective knowledge and acceptance. In a meta-analytic review, Bamberg and Moser (2006) concluded that knowledge is a necessary precursor to pro-environmental behavior, but it alone is inadequate to explain behavior, especially when the construct is conceptualized in an insufficient and methodologically flawed manner.

\subsection{Statement of the Problem}

In general, knowledge has an impact on behavior and this has been adequately shown in research. However, most researchers do not make a distinction between objective and subjective knowledge in examining the impact (Flynn \& Goldsmith, 1999; Pieniak et al., 2006). House et al. (2004) highlighted inconsistent and limited conceptualization of the knowledge construct as a major flaw in studies linking knowledge to PEB, where variation among researchers in defining and measuring knowledge could have contributed to conflicting and inconclusive results regarding its actual influence. In establishing the knowledge-behavior link, many researchers did not take into account the interplay of pro-environmental facts and information with one's personal experience, value systems and attitudinal, motivational, emotional, social, and economic variables, all of which are very closely tied to the concept of knowledge (Kollmuss \& Agyeman, 2002). Another factor often overlooked is the dimensionality of knowledge which has remained untested in many studies. Treating knowledge as a unidimensional socio-cognitive element represented in a single summated score with limited evidence of construct validity may have confounded the findings on the knowledge-behavior causal link, and constricts the interpretability of the results. Such methodological flaws would have watered down the expected effect of knowledge on behavior.

While it is easier to measure objective knowledge through the testing of factual information using True-False or multiple-choice items, it is harder to capture the essence of subjective knowledge accurately. Authors agreed that the measurement of subjective knowledge in research has been less than definitive (Kollmuss \& Agyeman, 2002), or done in an "ad hoc manner" (Flynn \& Goldsmith, 1999, p. 57), and this has led to large discrepancies in the results (Newhouse, 1991). The authors stressed the importance of developing a valid and reliable measure of the construct that is adaptable to a variety of survey needs. In the study of green computing behavior, it is very important that the subjective knowledge concept be drawn from the multidimensional nature of green computing itself in order to determine more precisely its impact on computer users' compliance with green practices. Given the increasing importance of green computing adoption, subjective green computing knowledge of a multidimensional nature should be adequately conceptualized and tested, especially among university students as they constitute a huge population of ICT users worldwide. University students engage in a large number of on and off campus computing activities that contribute significantly to global carbon emission. Accordingly, it must be ascertained that they possess the knowledge to use ICT effectively in responsible and eco-friendly ways as this knowledge impacts their pro-environmental computing practices. At present, little research is available to inform us about the nature and state of their subjective green computing knowledge and its relationship with PEB.

\subsection{Research Objectives}

This study, therefore, was an attempt to address the preceding concerns by examining subjective knowledge as a multidimensional construct and establishing its relationship with pro-environmental computing behavior. The specific objectives were as follows:

(1) To explore the underlying structure of subjective green computing knowledge reported by Malaysian university students;

(2) To validate the psychometric properties of students' subjective green computing knowledge in terms of the reliability, convergent validity and discriminant validity of the measure; and

(3) To examine the relationship between students' subjective green computing knowledge and their reported PEB.

\subsection{Research Framework and Hypotheses}

The research drew its theoretical underpinnings partly from Murugesan's (2008) notion of green computing as a multidimensional concept. Relative to this notion, subjective knowledge of green computing should accordingly reflect elements of multidimensionality. In the study's context, subjective knowledge was conceptualized to constitute what university students think they know about green computing in three important dimensions: (i) its basic vocabulary, (ii) nature of computers that impacts on the environment, and (iii) e-waste. A knowledgeable student would highly rate his or her level of knowledge on characteristics of computers that negatively affect the environment reflected in items such as "the amount of energy used by computers," and "the hazardous chemicals used in manufacturing computers." In terms of e-waste, subjective knowledge was associated with how the 
student rated his or her level of knowledge about "organizations that take care of e-waste," "e-waste management programs," and "computer hardware recycling programs." Finally, students' self-assessed knowledge of green computing vocabulary, reflected in their rating of the terms "green PC," "carbon footprint," and "e-waste," would also add up to the multidimensionality of green computing subjective knowledge.

The preceding observations argue for the likelihood of subjective knowledge of green computing being a multidimensional construct. Based on Murugesan (2008), it is very likely that it constitutes three sub-constructs, namely knowledge about the nature of computers those impacts on the environment, knowledge about e-waste, and knowledge of basic green computing vocabulary. And given the empirical evidence supporting the influence of subjective knowledge on PEB, the measure of subjective knowledge in this study was therefore anticipated to influence pro-environmental green computing behavior. Based on the theoretical underpinnings, the following research hypotheses were posed:

$\mathrm{H}_{1}$ : Subjective knowledge of green computing is a multidimensional construct comprising three interrelated dimensions.

$\mathrm{H}_{2}$ : The measure of multidimensional subjective green computing knowledge is construct-valid.

$\mathrm{H}_{3}$ : Pro-environmental behavior in green computing is influenced by subjective knowledge.

\section{Method}

\subsection{Sample}

The data for this study were obtained from 842 undergraduate students attending ten different public universities in Malaysia. A majority of the sample were female (58\%); 87\% aged 25 years or below. Malaysians made up the majority (66\%), while the rest were international students. The respondents had at least three years of experience in using computers, and were pursuing various academic disciplines. To meet the research objectives, the sample was split into two random halves $\left(n_{1}=400\right.$ and $\left.n_{2}=442\right)$. Data from the first sub-sample were used to establish the proposed underlying structure of subjective knowledge, hence addressing research objective one. The other half of the data was utilized for validation and structural modeling to address the last two research hypotheses. The sample size was deemed adequate for the application of dimensionality analysis and structural equation modeling (SEM) to address the research objectives.

\subsection{Measures}

To collect the data, we used a self-reported 16-item questionnaire measuring university students' subjective knowledge of green computing and PEB. The items were primarily drawn from an extensive review of literature on green computing, and were used in three previous studies on green computing knowledge and awareness (Tunku-Ahmad et al., 2013a; Bello, Tunku-Ahmad, \& Nordin, 2013; Tunku-Ahmad, Bello, \& Nordin, 2013b). As such, the items had been empirically tested a number of times prior to being selected in the present study.

Subjective knowledge: Twelve items representing the three hypothesized dimensions (i.e. vocabulary, nature of computers and e-waste) were used to assess subjective knowledge. Students rated the levels of their knowledge of these items on 5 response categories, i.e. "High," "Quite High," "Moderate," "Low" and "None." The vocabulary items were "green PC," "carbon footprint," "carbon-free computing," and "e-waste," while those assessing the e-waste dimension were "organizations that take care of e-waste," "e-waste management programs," "EPEAT-certified products," and "hardware recycling programs." Finally the items on nature of computers were "the negative impact of computers on the environment," "amount of energy used by computers," "hazardous chemicals used in manufacturing computers," and "energy saving features of a PC/laptop."

Pro-environmental behavior (PEB): Four Likert items were used to assess students' engagement in eco-friendly computing behaviors, i.e. computer purchasing practices and disposal of old hardware, which served as the endogenous variable. The four items were: "I buy ENERGY STAR computer hardware," "I buy computer hardware certified by EPEAT," "I donate old computer hardware to schools or organizations," and "I recycle old computer equipment." The reliability index of the PEB construct was adequate at alpha $=.74$.

\subsection{Data Analysis}

The study first conducted dimensional analysis using Principal Component Analysis (PCA) to explore the underlying structure of the responses. Next a three-stage Structural Equation Modeling using the AMOS (version 16) model-fitting program was applied to validate the measurement of subjective knowledge and test its influence on PEB. The study ran a confirmatory factor analysis and a full-fledged modeling to verify the adequacy of the hypothesized measurement model and the structural model. The hypothesized models were estimated using the covariance matrix derived from the data. Thus, the estimation procedures employed satisfied 
the underlying statistical distribution theory, hence yielding estimates of defensible properties.

\section{Results}

\subsection{Underlying Structure of Students' Subjective Knowledge of Green Computing}

Table 1 shows the descriptive statistics of the items included in the dimensionality reduction. Since the maximum possible score for each item is 5 , the mean score of all items appeared to fall below the hypothetical mean of 2.5. In particular, the mean score of the items associated with the dimension "green computing vocabulary" was less than .55. This means that the respondents reported having very low levels of green computing vocabulary. Additionally, the value of Cronbach's alpha (which is the internal consistency index of the responses to the related items) was reasonably high. The minimum value of the reliability index was .77, which exceeded the critical cut-score of .70 for a reliable measure of alpha.

Table 1. Subjective knowledge dimensions and item statistics

\begin{tabular}{|c|c|c|c|c|c|}
\hline Code & Dimension and Indicators of Subjective Knowledge & Alpha & Mean & $\mathrm{SD}$ & $\begin{array}{c}\text { Factor } \\
\text { Loading* }\end{array}$ \\
\hline & Sreen Computing Vocabulary & & & & \\
\hline a1 & - Green PC & & .50 & .92 & -.86 \\
\hline $\mathrm{a} 2$ & - Carbon footprint & .88 & .54 & .93 & -.86 \\
\hline a3 & - Carbon-free computing & & .49 & .90 & -.90 \\
\hline \multirow[t]{2}{*}{$\mathrm{a} 4$} & - E-Waste & & .55 & .96 & -.82 \\
\hline & Nature of Computers & & & & \\
\hline a5 & - The negative impact of computers on the environment & & 2.26 & 1.12 & .71 \\
\hline a6 & - The amount of energy used by computers & .77 & 2.41 & 1.08 & .88 \\
\hline a7 & - The hazardous chemicals used in manufacturing computers & & 1.91 & 1.13 & .72 \\
\hline \multirow[t]{2}{*}{ a8 } & - The energy-saving features of a PC/laptop & & 2.19 & 1.08 & .75 \\
\hline & -Waste & & & & \\
\hline a9 & - Organizations that take care of e-waste & & 1.36 & 1.21 & .78 \\
\hline a10 & - E-waste management programs & .85 & 1.15 & 1.14 & .89 \\
\hline a11 & - EPEAT-registered products & & 1.25 & 1.14 & .81 \\
\hline a12 & - Computer hardware recycling programs & & 1.20 & 1.11 & .80 \\
\hline
\end{tabular}

* Extracted from Principal Component Analysis.

Principal component analysis (PCA) was conducted to explore the underlying structure of responses to the 12 subjective knowledge items among the first sub-sample of 400 undergraduates. The results of the analysis indicated that the degree of intercorrelation among the items measuring students' self-rated knowledge of green computing justified the use of PCA $[\chi 2(66)=1934, \mathrm{p}=.001$, KMO measure of sampling adequacy $=.85]$. The results were obtained from a maximum likelihood procedure using the oblimin method of axis rotation.

As expected, the PCA (Table 2) extracted three underlying factors. The reproduced correlation matrix appeared to best fit the intercorrelation among the indicators, accounting for $68 \%$ of the total variance. The variance of the first dimension (green computing vocabulary), with the largest eigenvalue was 4.79 , while the eigenvalues of the other two dimensions were 1.95 (nature of computers) and 1.43 (e-waste) respectively. A parallel analysis (Matsunaga, 2010) was conducted, and the results supported the existence of a three-factor solution in the data set. 
Table 2. Eigenvalues and proportion of variance explained

\begin{tabular}{|c|c|c|c|c|c|c|c|}
\hline \multirow{2}{*}{ Factor } & \multicolumn{3}{|c|}{ Initial Eigenvalues } & \multicolumn{3}{|c|}{ Extraction Sums of Squared Loadings } & \multirow{2}{*}{$\begin{array}{c}\begin{array}{c}\text { Rotation Sums } \\
\text { of Squared } \\
\text { Loadings }\end{array} \\
\text { Total }\end{array}$} \\
\hline & Total & $\%$ of Variance & Cumulative $\%$ & Total & $\%$ of Variance & Cumulative \% & \\
\hline 1 & 4.788 & 39.897 & 39.897 & 4.788 & 39.897 & 39.897 & 3.621 \\
\hline 2 & 1.954 & 16.283 & 56.180 & 1.954 & 16.283 & 56.180 & 3.603 \\
\hline 3 & 1.427 & 11.888 & 68.067 & 1.427 & 11.888 & 68.067 & 3.204 \\
\hline 4 & .702 & 5.849 & 73.917 & & & & \\
\hline 5 & .606 & 5.051 & 78.967 & & & & \\
\hline 6 & .496 & 4.133 & 83.100 & & & & \\
\hline 7 & .425 & 3.545 & 86.645 & & & & \\
\hline 8 & .407 & 3.393 & 90.037 & & & & \\
\hline 9 & .373 & 3.107 & 93.145 & & & & \\
\hline 10 & .310 & 2.581 & 95.725 & & & & \\
\hline 11 & .292 & 2.437 & 98.162 & & & & \\
\hline 12 & .221 & 1.838 & 100.000 & & & & \\
\hline
\end{tabular}

Extraction Method: Principal Component Analysis.

The PCA found that each factor loading, which indicates the correlation of the item with the factor, was statistically significant (Table 1). The estimated factor loadings were large enough to be of practical importance; even the weakest loading ("The hazardous chemicals used in manufacturing computers"; $\lambda=.724$ ) was statistically significant, at $\mathrm{p}=.01$. Within each dimension, the analysis produced item loadings in the same consistent direction, resulting in a solution that was free from variable-specific factors.

The four strong and significant loadings on the first rotated factor suggested the existence of one common aspect of green computing knowledge, which is e-waste. The empirical clustering of variables that loaded on this dimension perfectly matched the logical grouping of items. Items representing students' subjective knowledge of green computing vocabulary, i.e. "green PC," "carbon footprint," "carbon-free computing" and "e-waste," significantly loaded on the second dimension. Finally, the commonality among the items that loaded on the third factor reflected students' self-assessed knowledge about the nature or characteristics of computers that have an impact on the environment.

\subsection{Measurement Validity of Subjective Green Computing Knowledge}

To test the validity of the subjective knowledge measure, a confirmatory factor analysis (CFA) was applied on the data drawn from the second sub-sample $(n=442)$. The results of the estimated measurement model indicated that the three-factor structure of subjective knowledge was adequate to represent the data. The goodness-of-fit of the model was reasonable, the relative Chi-square $=3.68$; RMSEA $=.078 ; \mathrm{CFI}=.95$. In other words, there was no evidence that the measurement model of subjective green computing knowledge was incorrect (Figure 1). 


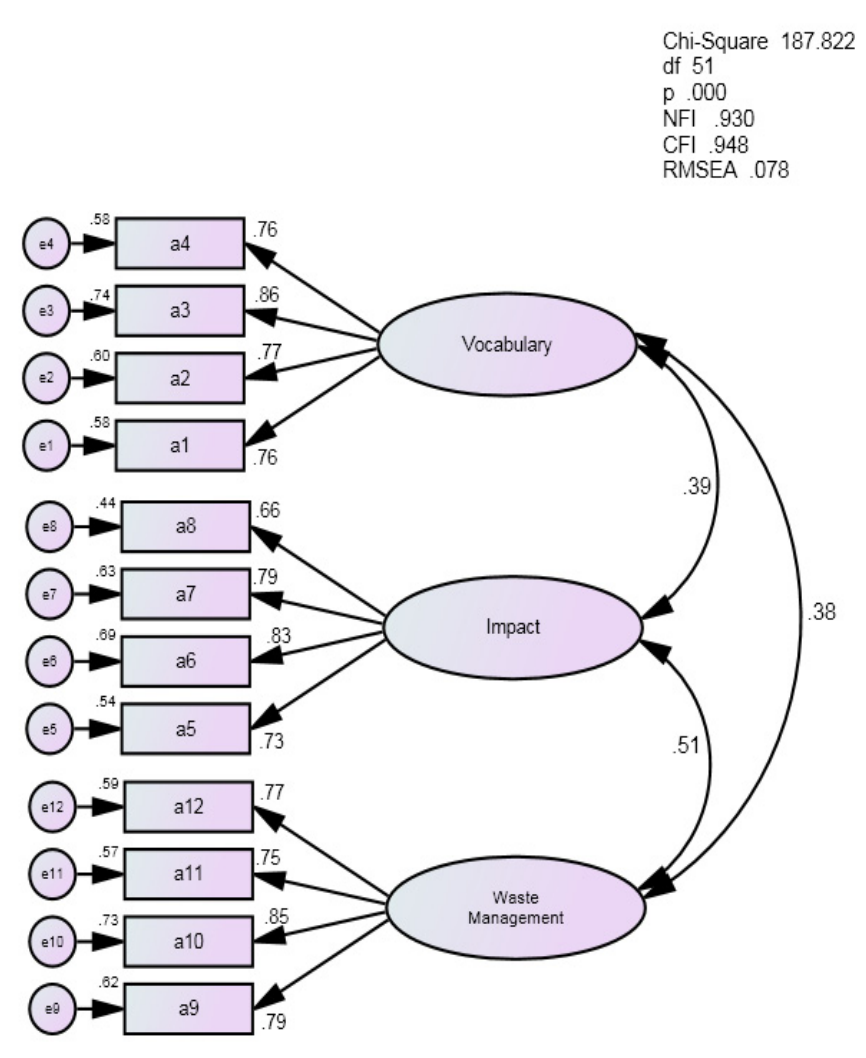

Figure 1. CFA results confirming a three-factor structure of subjective green computing knowledge

Table 3 provides additional evidence regarding the adequacy of the measurement model in terms of its convergent validity and discriminant validity. The data (along the diagonal) indicated that the AVE of each construct exceeded the convergent validity threshold of 0.5. AVE (average variance extracted) is an indicator of the validity of a set of items in representing a construct. AVE denotes the average amount of variation that a construct is able to explain through its indicators, which are the related items. In addition, the measurement possessed the property of discriminant validity since the AVEs were larger than the values of the corresponding shared variances (values above the diagonal). Furthermore, the inter-factor correlations indicated that subjective knowledge was a multidimensional construct consisting of distinct but inter-related dimensions.

Table 3. Convergent validity, discriminant validity and inter-factor correlations among the constructs of subjective green computing knowledge

\begin{tabular}{llccc}
\hline & Dimension/Construct & 1 & 2 & 3 \\
\hline 1 & Vocabulary & 0.62 & 0.15 & 0.14 \\
2 & Nature of Computers & 0.39 & 0.57 & 0.26 \\
3 & E-waste & 0.38 & 0.51 & 0.63 \\
& Composite Reliability & 0.87 & 0.84 & 0.87
\end{tabular}

Note: (i) Shown diagonally are the average variances extracted (AVEs) for each construct; below the diagonal is the correlation matrix; above the diagonal is the shared variance matrix; (ii) All AVEs were larger than the shared variances. 


\subsection{Adequacy of the Hypothesized Subjective Green Computing Knowledge-PEB Structural Model}

Figure 2 summarizes the Structural Equation Modeling results of subjective green computing knowledge $\rightarrow$ PEB model that addressed the third research hypothesis. The confirmatory modeling showed consistency of the hypothesized causal relationships with the data (relative Chi-square $=3.2$; RMSEA $=.071$; CFI $=.929$; NFI $=.901$ ). All these fit indices satisfied their critical cut-scores. The results, therefore, indicated a fitting model of the relationship between subjective knowledge and PEB. Additionally, the analysis revealed that collectively the three exogenous variables (GC vocabulary, nature of computers and e-waste) explained $37 \%$ of the variability of the reported PEB among the respondents.

The parameter estimates of the hypothesized model were free from offending values with uncorrelated errors. All path coefficients of the causal structure were statistically significant at .01 level, and of practical importance. The standardized path coefficient of subjective knowledge $\rightarrow$ PEB was substantial and statistically significant, $\beta=$ 0.61 .

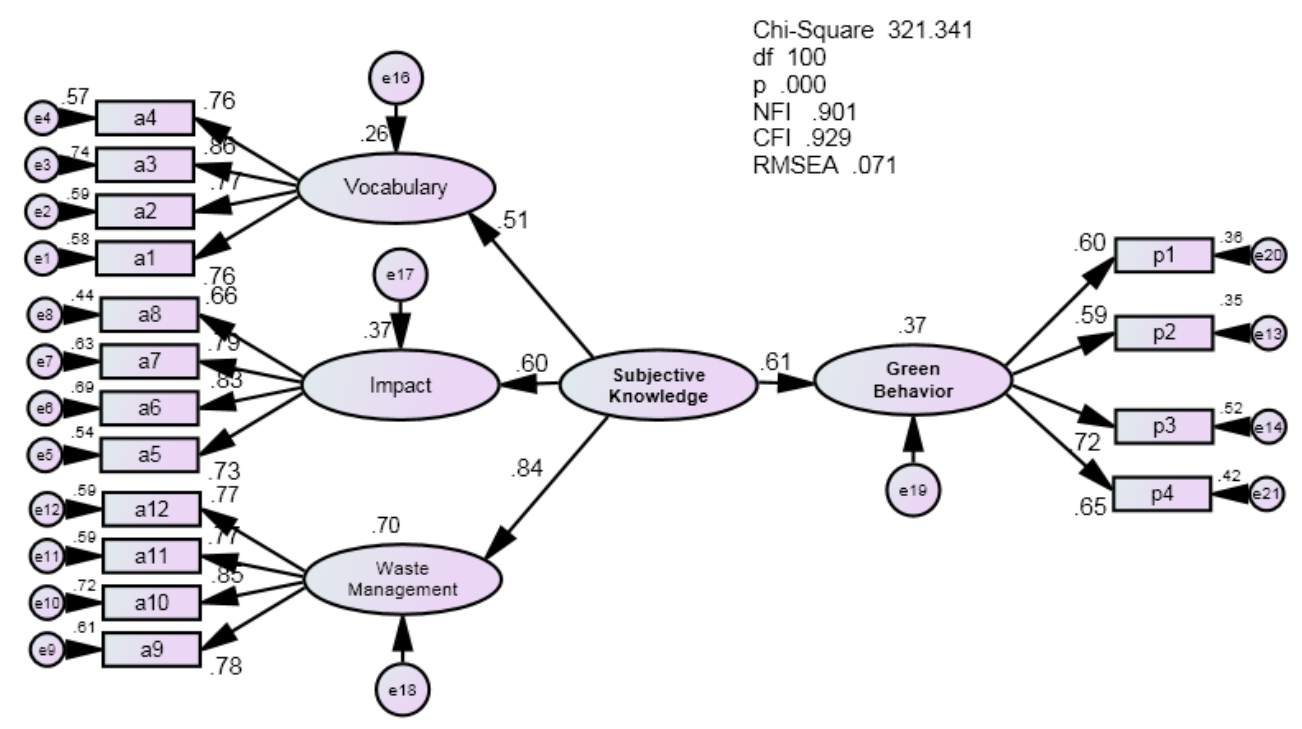

Figure 2. SEM results of the hypothesized subjective gc knowledge-PEB model

Table 4 summarizes the results of the CFA and SEM analyses. Both data analysis results supported the expected causal relationships among the green computing variables. Specifically, this study found subjective knowledge of green computing to be a valid and reliable multidimensional construct that was systematically associated with PEB.

Table 4. Summary of CFA and SEM hypothesis testing results

\begin{tabular}{clc}
\hline & \multicolumn{1}{c}{ Hypothesis } & Results \\
\hline $\mathrm{H}_{1}$ & $\begin{array}{l}\text { Subjective knowledge of green computing is a multidimensional } \\
\text { construct comprising three interrelated dimensions. }\end{array}$ & Supported \\
$\mathrm{H}_{2}$ & $\begin{array}{l}\text { The measure of multidimensional subjective green computing } \\
\text { knowledge is construct-valid. }\end{array}$ & Supported \\
$\mathrm{H}_{3} \quad \begin{array}{l}\text { Pro-environmental behavior in green computing is influenced by } \\
\text { subjective knowledge. }\end{array}$ & Supported \\
\hline
\end{tabular}

\section{Discussion}

The first aim of the study was to explore and validate the hypothesized three-factor structure of subjective green computing knowledge. The evidence pointed to a three-dimensional construct that is valid and reliable, thereby 
extending current understanding of the nature of knowledge in several ways. First, it offers empirical evidence that subjective knowledge is a multidimensional construct, as implicitly hinted at in earlier works (Bamberg \& Moser, 2006; House et al., 2004; Kollmuss \& Agyeman, 2002). Second, there appeared to be three distinct but related dimensions of the subjective knowledge examined in the study, which comprised knowledge of GC vocabulary, knowledge of nature of computers, and knowledge of e-waste. Third based on the results, the brief instrument on subjective GC knowledge used in the study is therefore practically useful in diagnostic and evaluative assessments of computer users' understanding of green computing.

The second aim was to examine the causal correlational influence of subjective GC knowledge on PEB. As expected, subjective knowledge was found to be related to students' PEB, where higher levels of subjective knowledge were reliably associated with eco-friendly computer purchasing and hardware disposal practices. Generally, this finding supports the notion that knowledge is an essential precondition to PEB, but more specifically it establishes the role of subjective knowledge in influencing PEB, hence corroborating previous research in this regard (Gámbaro, Ellis, \& Prieto, 2013; House et al., 2004; Moon \& Balasubramanian, 2000; Pieniak, 2006). It was discovered that self-constructed knowledge triggered a strong inclination to act pro-environmentally, a relationship earlier pointed out by Kollmuss and Agyeman (2002).

Since subjective knowledge has been found to be a multidimensional construct, researchers should not make the mistake of using and interpreting composite scores to assign end-users to levels of green computing knowledge. Instead, the results suggest the use of three separate scores - on vocabulary, computer nature and e-waste- as indicators. An end-user with a high score on GC vocabulary may not perform as well on the e-waste dimension. Such a user may perceive the level of their knowledge about green PC, carbon footprint, carbon-free computing and e-waste as high, but may report poor knowledge of hardware recycling and e-waste management programs. This means that each dimension of GC knowledge should be examined individually and interpreted within the limits of its own framework. Otherwise, some important causal links may be overlooked.

Additionally, subjective knowledge was found to be a strong driver of behavior; and if the observation that subjective knowledge is a function of direct experience holds water, then this finding merits some attention. The finding as such points to a need to revisit the curriculum implementation of environmental education through traditional pedagogical approaches such as lectures and conventional campaigns. Such approaches may work well to impart objective knowledge about PEB and associated concepts, but may be limited in addressing the knowledge-behavior gap. Kollmuss and Agyeman (2002) suggest that the use of pragmatic, non-traditional approaches may be more effective in bringing about behavior change. In line with their suggestion, experiential learning may promise more success in the bridging of knowledge, attitudes and actions.

Constrained within the limitations of the ex-post facto design, the results of the study have produced additional paths for research on environmental knowledge and environmental education in general, and green computing in particular. Several guidelines are thereby offered for future research in relevant areas. First there is a need to further examine and refine the conception of subjective knowledge, as well as the nature of eco-friendly computing behaviors, to be more holistically representative of green computing and PEB. Second, empirical cross-validation of subjective green computing knowledge of a multidimensional nature is necessary to determine the extent of its usefulness in influencing PEB in different contexts and cultures. Finally, it is also important that studies be conducted to understand the determinants of GC knowledge as well as the process of acquiring it among different groups of computer users.

\section{References}

Aertsens, J., Mondelaers, K., Verbeke, W., Buysse, J., \& Van Huylenbroeck, G. (2011). The influence of subjective and objective knowledge on attitude, motivations and consumption of organic food. British Food Journal, 113(11), 1353-1378. http://dx.doi.org/10.1108/00070701111179988

Aggarwal, S., Garg, M., \& Kumar, P. (2012). Green computing is smart computing: A survey. International Journal of Emerging Technology and Advanced Engineering, 2(2), 297-303. Retrieved from http://www.ijetae.com/files/Volume2Issue2/IJETAE_0212_51.pdf

Alba, J., \& Hutchinson, J. W. (2000, September). Knowledge calibration: What consumers know and what they think they know. Journal of Consumer Research, 27, 123-156. http://dx.doi.org/10.1086/314317

Bamberg, S., \& Moser, G. (2006). Twenty years after hines, hungerford, and tomera: A new meta-analysis of psychosocial determinants of pro-environmental behavior. Journal of Environmental Psychology, 27, 14-25. http://dx.doi.org/10.1016/j.jenvp.2006.12.002

Bello, A., Tunku-Ahmad, T. B., \& Nordin, M. S. (2013). Knowledge of green computing among university 
students and lecturers in a Malaysian public university. GSTF International Journal on Computing, 3(1), 109-11.

Blackwell, R. D., Miniard, P. W., \& Engel, J. F. (2001). Consumer behaviour (9th ed.). New York: HarcourtCollege Publishers.

Boccaletti, S., \& Moro, D. (2000). Consumer willingness-to-pay for gm food products in Italy. AgBioForum, 3(4), 259-267. Retrieved from http://www.agbioforum.org

Brucks, M. (1985). The effects of product class knowledge on information search behaviour. Journal of Consumer Research, 12, 1-16. http://dx.doi.org/10.1086/209031

Carlson, J. P., Vincent, L. H., Hardesty, D. M., \& Bearden, W. O. (2009). Objective and subjectiveknowledge relationships: A quantitative analysis of consumer research findings. Journa lof Consumer Research, 35(5), 864-76. http://dx.doi.org/10.1086/593688

Claiborne, R. (2009, August 2). U.S. electronic waste gets sent to Africa. ABC News. Retrieved from http://abcnews.go.com/GMA/Weekend/story?id=8215714

Courtney, M. (2008, August 28). Knowledge gap in green IT is hampering further adoption. Computing.co.uk. Retrieved

from http://www.computing.co.uk/ctg/news/1859055/knowledge-gap-green-it-hampering-adoption.

Ellen, P. S. (1994). Do we know what we need to know: Objective and subjective knowledge effects on pro-ecological behaviors. Journal of Business Research, 30(1), 43-52. http://dx.doi.org/10.1016/0148-2963(94)90067-1

Feick, L., Park, C. W., \& Mothersbaugh, D. L. (1992). Knowledge and knowledge of knowledge: What we know, what we think we know, and why the difference makes a difference. Advances in Consumer Research, 19, 190-192.

Flynn, L., \& Goldsmith, R. (1999). A short, reliable measure of subjective knowledge. Journal of Business Research, 46, 57-66. http://dx.doi.org/10.1016/S0148-2963(98)00057-5

Gámbaro, A., Ellis, A., \& Prieto, V. (2013). Influence of subjective knowledge, objective knowledge and health consciousness on olive oil consumption: A case study. Food and Nutrition Sciences, 4(4), 445-453. http://dx.doi.org/10.4236/fns.2013.44057

Government News. (2011, March 8). Lack of knowledge on green IT. Retrieved from http://www.governmentnews.com.au/2011/03/08/article/Lack-of-knowledge-on-green-IT/CPHLPYGXBT.h tml

House, L., Lusk, J., Jaeger, S., Traill, W. B., Moore, M., Valli, C., . . . Yee, W. M. S. (2004). Objective and subjective knowledge: Impacts on consumer demand for genetically modified foods in the United States and the European Union. AgBioForum, 7(3), 113-123. Retrieved from http://www.agbioforum.org/v7n3/v7n3a03-house.htm

Jenkin, T. A., Webster, J., \& McShane, L. (2011). An agenda for green information technology and systems research. Information and Organization, 21, 17-40. http://dx.doi.org/10.1016/j.infoandorg.2010.09.003

Kollmuss, A., \& Agyeman, J. (2002). Mind the gap: Why do people act environmentally and what are the barriers to pro-environmental behavior? Environmental Education Research, 8(3), 239-260. http://dx.doi.org/10.1080/13504620220145401

Laroche, M., Tomiuk, M. A., Bergeron, J., \& Barbaro-Forleo, G. (2002). Cultural differences in environmental knowledge, attitudes, and behaviours of Canadian consumers. Canadian Journal of Administrative Services, 19(3), 267-283. http://dx.doi.org/10.1111/j.1936-4490.2002.tb00272.x

Maleki, A., \& Karimzadeh, S. (2011). A survey of relationship between the environmental attitudes and environmental knowledge and energy consumption behavior among citizens of Urmia, Westazerbaijan, Iran. International Journal of Social Sciences and Humanity Studies, 3(1), 27-37.

Matsunaga, M. (2010). How to factor-analyze your data right: Do's, don'ts, and how-to's. International Journal of Psychological Research, 3(1), 97-110.

McDougall, G. H. G. (1993). The green movement in Canada: Implications for marketing strategy. Journal of International Consumer Marketing, 15(3), 69-87.

Moon, W., \& Balasubramanian, S. K. (2001). Public perceptions and willingness-to-pay a premium for non-gm 
foods in the US and UK. AgBioForum, 4(3\&4), 221-231.

Murugesan, S. (2008). Harnessing green IT: Principles and practices. IEEE IT Professional, 10(1), 24-33. http://dx.doi.org/10.1109/MITP.2008.10

Newhouse, N. (1991). Implications of attitude and behavior research for environmental conservation. The Journal of Environmental Education, 22(1), 26-32. http://dx.doi.org/10.1080/00958964.1990.9943043

Pieniak, Z., Aertsens, J., \& Verbeke, W. (2010). Subjective and objective knowledge as determinants of organic vegetables consumption. Food Quality and Preference, 21, 581-588. http://dx.doi.org/10.1016/j.foodqual.2010.03.004

Pieniak, Z., Verbeke, W., Brunso, K., \& Olsen, S. O. (2006). Consumer knowledge and interest in information about fish. In J. Luten, C. Jacobsen, K. Bekaert, A. Saeobo, \& J. Oehlenschlager (Eds.), Seafood research from fish to dish: Quality, safety and processing of wild and farmed fish (pp. 229-241). Wageningen: WageningenAcademic Publisher.

Radecki, C. M., \& Jaccard, J. (1995). Perceptions of knowledge, actual knowledge, and information search behavior. Journal of Experimental Social Psychology, 31, 107-138. http://dx.doi.org/10.1006/jesp.1995.1006

Rogers, E. M. (2003). Diffusion of Innovations (5th ed.). New York: Free Press.

Sirieix, L., Delanchy, M., Remaud, H., \& Zepedad, L. (2011). How do consumers react in front of individual and combined sustainable food labels? A UK focus group study. Working-Paper-Umr Moisa. Retrieved from http://www1.montpellier.inra.fr/bartoli/moisa/bartoli/download/moisa2011_pdf/WP_1_2011.pdf

Thapa, B., Graefe, A. R., \& Meyer, L. A. (2005). Moderator and mediator effects of scuba diving specialization on marine-based environmental knowledge-behavior contingency. The Journal of Environmental Education, 37(1), 53-67. http://dx.doi.org/10.3200/JOEE.37.1.53-68

The China Daily. (2011, November 16). Lead levels in children linked to rise in e-waste profits. Retrieved from http://www.chinadaily.com.cn/cndy/2011-11/16/content_14101761.htm.

Tunku-Ahmad, T. B., Nordin, M. S., \& Bello, A. (2013a). The state of green computing knowledge among students in a Malaysian public university. Journal of Asian Scientific Research, 3(8), 831-842. Retrieved from http://www.aessweb.com/archives.php?m=August2013\&id=5003

Tunku-Ahmad, T. B., Nordin, M. S., \& Bello, A. (2013b). Exploring Malaysian university students' awareness of green computing. GSTF International Journal on Education, 1(2), 92-102. http://dx.doi.org/10.5176/2345-7163_1.2.34

Vervynckt, M. (2013). Electronic waste in Ghana: A toxic opportunity? Internal Voices. Retrieved from http://www.internalvoices.org/international-issues/item/117-electronic-waste-in-ghana-a-toxic-opportunity

Xiao, J. J., Serido, J., \& Shim, S. (2010). Financial education, financial knowledge, and risky credit behavior of college students. In D. J. Lamdin (Ed.), Consumer Knowledge and Financial Decisions: Lifespan Perspectives (pp. 113-128). New York: Springer.

\section{Copyrights}

Copyright for this article is retained by the author(s), with first publication rights granted to the journal.

This is an open-access article distributed under the terms and conditions of the Creative Commons Attribution license (http://creativecommons.org/licenses/by/3.0/). 